\title{
Activity demands and instability are the most important factors for recommending to treat $\mathrm{ACL}$ injuries with reconstruction
}

\author{
Hanna Tigerstrand Grevnerts ${ }^{1,2} \cdot$ Anne Fältström $^{2,3} \cdot$ Sofi Sonesson $^{2} \cdot$ Håkan Gauffin $^{5} \cdot$ Siw Carlfjord $^{4} \cdot$ Joanna Kvist $^{2}$
}

Received: 6 September 2017 / Accepted: 24 January 2018 / Published online: 6 February 2018

(c) The Author(s) 2018. This article is an open access publication

\begin{abstract}
Purpose The purpose of the study was to (1) study and compare the factors that Swedish orthopaedic surgeons and physical therapists consider important for recommending ACL reconstruction and, (2) to assess how orthopaedic surgeons and physical therapists consider their own and each others, as well as patients', roles are in the treatment decision.

Methods A web-based survey assessing the relevance of 21 predetermined factors, in the choice to recommend ACL reconstruction, was sent to orthopaedic surgeons and physical therapists. Respondents were also asked to rate the importance of the assessment made by themselves, the other clinician (physical therapists rated the importance of surgeons, surgeons rated the importance of physical therapists), and the patients' preferences.

Result Orthopaedic surgeons agreed of eight, and physical therapists of seven factors as important in the choice to recommend ACL reconstruction. The factors both groups reported as important were; "patient's wishes to return to contact/pivoting sports", "instability in physical activity", "instability in activities of daily living despite adequate rehabilitation", "physically demanding occupation", and "young age". Both professions rated their own and each others assessments as well as patient's wishes as important for the decision to recommend ACL reconstruction.

Conclusion Orthopaedic surgeons and physical therapists agree about factors that are important for their decision to recommend ACL reconstruction, showing that both professions share a common ground in perceptions of factors that are important in recommending ACL reconstruction.
\end{abstract}

Level of evidence Diagnostic study: Level III.

Keywords Knee $\cdot$ Anterior cruciate ligament injury $\cdot$ Treatment decision $\cdot$ ACL reconstruction

Electronic supplementary material The online version of this article (https://doi.org/10.1007/s00167-018-4846-1) contains supplementary material, which is available to authorized users.

Hanna Tigerstrand Grevnerts

Hanna.tigerstrand.grevnerts@liu.se

1 Department of Activity and Health, Linköping University, 58183 Linköping, Sweden

2 Division of Physiotherapy, Department of Medical and Health Sciences, Linköping University, 58183 Linköping, Sweden

3 Region Jönköping County, Rehabilitation Centre, Ryhov County Hospital, Jönköping, Sweden

4 Division of Social Sciences, Department of Medical and Health Sciences, Linköping University, 58183 Linköping, Sweden

5 Orthopaedic Department Linköping University Hospital, Department of Clinical and Experimental Medicine, Linköping University, 58183 Linköping, Sweden

\section{Abbreviations}

ACL Anterior cruciate ligament

ACL-R Anterior cruciate ligament reconstruction

\section{Introduction}

An anterior cruciate ligament (ACL) injury is often treated initially with physical therapy, and in many cases followed by an ACL reconstruction (ACL-R) plus post-operative rehabilitation [22]. Today, there is no clear evidence of which treatment, surgery followed by rehabilitation or rehabilitation alone, is superior, or on which basis either treatment should be chosen. Noyes proposed in the 1980s that onethird of ACL-injured patients would function well without surgical treatment $[22,23]$. In a recent randomised clinical trial, there was equivalent self-reported outcome at 2 and 5 years after injury among patients treated with ACL-R or rehabilitation only $[9,10]$. A treatment decision algorithm, 
based on clinical performance tests and patient-reported outcome questionnaires, aiming to identify appropriate patients for surgical or nonsurgical treatment has been developed at the University of Delaware [7, 13, 14]. Still, when using the screening algorithm, $70 \%$ of the patients who chose not to undergo ACL-R despite being identified as appropriate candidates for surgical treatment, showed good patient-reported outcome and had returned to their previous activity level at 1 year follow-up [21]. This implies that identifying the right treatment for the right patient is complex and challenging.

There are several guidelines published from different countries, where knee joint instability, sporting demands or insufficient/failed rehabilitation, are important factors impacting on the decision to recommend ACL-R [2, 18, 20, 25].

The importance of providing rehabilitation treatment for this group of patients (with or without surgery), underscores the role of the physical therapist as an important caregiver $[4,16]$. The physical therapist's role in the treatment decision has not yet been explored. There is also a need to study the factors that physical therapists consider are important to the recommendation for ACL-R, and how orthopaedic surgeons and physical therapists rate the importance of each other's assessment in the choice of treatment. Physical therapists work closely with patients through rehabilitation, and may influence patients' views regarding preferred treatment. So, it is important to understand physical therapists' views regarding how treatment decisions are made. This information might also enhance collaboration between orthopaedic surgeons and physical therapists. For example, physical therapists often have detailed knowledge of the patient's objective knee function; knowledge that might be of value in the treatment decision making process.

The aims of this descriptive survey study were: (1) to study and compare the factors Swedish orthopaedic surgeons and physical therapists consider important for recommending ACL-R, and (2) to assess how important orthopaedic surgeons and physical therapists consider their own and each others', as well as patients', roles are in the treatment decision.

\section{Materials and methods}

In this descriptive study, an online survey (Online Appendix 1, Online Appendix 2) was sent to orthopaedic surgeons and physical therapists who were active in treating patients with ACL injury.

\section{Survey}

The first draft of the survey was constructed by a group of researchers with extensive research experience in ACL injury. The predetermined factors were based on research by Swirtun et al. [27], that revealed factors that patients believed to be important for the choice to undergo ACLR. These factors were influential to the factors that has been used in other studies (unpublished material) and reviewed by researchers, before use in the present survey. To obtain face validity, the survey was sent to four orthopaedic surgeons (active in spine, shoulder and achilles tendon surgery, one with previous experience in ACL-R), and five physical therapists (two with extensive experience in treating patients with ACL injuries and three with experience in general musculoskeletal disorders). The orthopaedic surgeons and physical therapists reviewed the questions and wording for content and clarity. Their comments lead to some minor changes and clarifications of the survey.

The final survey that was sent to orthopaedic surgeons and physical therapists contained sociodemographic questions, questions about experience in treating patients with ACL injury, knowledge of ACL treatment guidelines, and 21 predetermined factors (Online Appendix 1, Online Appendix 2) that should be graded regarding importance to recommend ACL-R. The predetermined factors were on a $0-3$ scale, were a higher grade corresponds to higher likeliness to recommend ACL-R. There was an open-ended question about which factor or combination of factors were considered the most important factors for the clinician to recommend ACL-R. Questions about patient rehabilitation and how physical therapists present their assessment findings to the orthopaedic surgeon, were included, as well as questions about how important the physical therapists and orthopaedic surgeons consider their own and the other profession's assessment, and the patient's wishes.

\section{Study participants}

Almost all (>90\%) orthopaedic surgeons who perform ACL-R in Sweden register their operative procedures in the Swedish national knee ligament register [28].. All surgeons registered as conducting ACL-R in the register, were contacted by email ( 236 email addresses). The number of surgeons actively performing ACL-R during 2013 and 2014, when the survey was conducted, was 160 and 152, respectively, implying that some registered email addresses might be to inactive surgeons or some surgeons might have had multiple registered email addresses. One email address was incorrect, resulting in 235 invitation email surveys being sent to orthopaedic surgeons. 
Physical therapists that were potentially active in treating patients with ACL injury were identified by the Swedish Society for Physical Activity and Sports Medicine, Swedish Football Physiotherapists Association, orthopaedic clinics over Sweden and through professional contacts. After the survey was sent, several physical therapists contacted the research group and gave email addresses for colleagues they knew treated patients with ACL injury (snowball recruitment), resulting in two additional rounds of mailings. In total, 951 emails were sent. Of the 951 physical therapists' email addresses, four were incorrect resulting in 947 invitation email surveys being sent to physical therapists. There were no checking to see if there were multiple addresses for a single respondent, and therefore, no certainty that there were 947 individual physical therapists who were approached to participate.

To improve generalizability, we invited orthopaedic surgeons and physical therapists who worked in the larger cities and smaller regions and counties in Sweden.

\section{Data collection}

All surveys were sent in April 2014. Up to two reminders were sent to participants who had not responded. The surveys were distributed by a secure web-based survey system (esMaker): version $3.0^{\odot}$ Entergate $\mathrm{AB}$, and were completed and returned anonymously.

This study had ethical approval from the Regional Ethical Review Board Dnr 2014 (71/31).

\section{Data analysis}

For ratings of the factors influencing the choice to recommend ACL-R, we dichotomized the responses to "no surgery" for orthopaedic surgeon and "little probability that I would recommend ACL reconstruction" for physical therapists (when the rating was 0 or 1 ) or "surgery" for orthopaedic surgeons and "great probability that I would recommend ACL reconstruction" for physical therapists (when the rating was 2 or 3) (Online Appendix 1, Online Appendix 2). If a respondent answered "surgery"/"great probability that I would recommend ACL reconstruction", we interpreted this as indicating that the factor was important for recommending ACL-R, and subsequently used the factor in the analysis of factors reaching clinical agreement.

Clinical agreement was defined as when $80 \%$ of respondents had chosen the same response option (after dichotomizing the answer options) [19].

We categorised answers to the open-ended question of factors that were important for choosing ACL-R into 1 of 6 categories (instability, patient focus, activity demands, other injuries, sociodemographic factors and objective measures). These categories were based on the experience from previous studies within the research group, and after reviewing the answers from this study. Categorization (and any further sub-categorization) was made by a physical therapist (HTG) with both clinical and research experience in treating ACL injuries. For each category, we examined whether it was described as a sole factor in the decision to recommend ACL-R, or as part of a cluster of factors that were considered together by the clinician as a basis for the decision to recommend ACL-R.

\section{Results}

There were 130 orthopaedic surgeons who responded to the email invitation (Table 1). Among these, 98 (75\%) accepted to participate, 7 declined (5\%) due to unspecified reasons, and 25 (19\%) declined due to not treating patients with ACL injury. Of the nonresponding orthopaedic surgeons there were 11 women and 94 men.

There were 595 physical therapists who responded to the email invitation (Table 1). Among these, 391 (66\%) accepted to participate, $38(6 \%)$ declined due to unspecified reasons, and $166(28 \%)$ declined due to not treating patients with ACL injury. Of the 352 nonresponding physical therapists, 201 were women and 151 were men.

Regarding the factors influencing the treatment decision-making process, orthopaedic surgeons reached clinical agreement for 8 factors, and physical therapists reached clinical agreement for 7 factors (out of a total of 21 factors). (Table 2).

Fifty-six of the 98 orthopaedic surgeons (57\%) answered the open-ended question (Table 3).

Three hundred and thirty-seven of the 391 physical therapists (86\%) answered the open-ended question (Table 3). A few comments were more specific to a certain activity, such as recommending ACL-R for patients that compete in alpine skiing or gymnastics, or for young women participating in soccer or floorball. It was reported as "instability in relation to the demands of the knee" or "return to activity with high risks or knee-demanding activity" depending on whether instability was mentioned in combination with the desire to return to the activity (Table 3 ).

Orthopaedic surgeons and physical therapists had very similar ratings for the impact of their own, each other's assessments, and the patient's wishes in the decision-making to recommend ACL-R (Fig. 1).

Regarding compliance to rehabilitation, 73 of 92 (79\%) orthopaedic surgeons stated that they often seek information about it, and do so by asking the patient. Sixty-five of $91(71 \%)$ orthopaedic surgeons stated that they sometimes or often read the patient's medical record to seek information about rehabilitation compliance, and 65 of 92 (70\%) 
Table 1 Sociodemographic data and experience in treating patients with ACL injury among responding orthopaedic surgeons and physical therapists

\begin{tabular}{lcc}
\hline & $\begin{array}{l}\text { Orthopaedic surgeons } \\
\text { Total: } 98 \\
n(\%)\end{array}$ & $\begin{array}{l}\text { Physical therapists } \\
\text { Total: } 391 \\
n(\%)\end{array}$ \\
\hline Gender (M/F) & $88(90) / 10(10)$ & $186(48) / 205(52)$ \\
Age (in years) & & \\
$<30$ & $0(0)$ & $57(15)$ \\
$31-45$ & $38(39)$ & $121(31)$ \\
$46-55$ & $31(32)$ & $144(37)$ \\
$>56$ & $29(30)$ & $68(17)$ \\
Experience ${ }^{\mathrm{a}}$ (in years) & & $31(8)$ \\
$<2$ & $7(7)$ & $64(17)$ \\
$2-5$ & $14(14)$ & $58(15)$ \\
$6-10$ & $19(19)$ & $232(60)$ \\
$>10$ & $58(59)$ & $18(5)$ \\
Patient volume during the last 6 months & \\
0 & $5(5)$ & $119(31)$ \\
$1-4$ & $5(5)$ & $175(45)$ \\
$5-15$ & $37(38)$ & $76(20)$ \\
$>15$ & $51(52)$ & $50(13)$ \\
Knowledge of guidelines & & $107(27)$ \\
International & $18(18)$ & $237(61)$ \\
National & $44(45)$ & $111(28)$ \\
Local & $63(64)$ & \\
No knowledge & $16(16)$ & \\
\hline
\end{tabular}

$A C L$ anterior cruciate ligament, $A C L-R$ anterior cruciate ligament reconstruction

${ }^{a}$ Experience (in years) for conducting anterior cruciate ligament reconstruction (surgeons) or for treating patients with an ACL injury (physical therapists)

${ }^{\mathrm{b}}$ The number of ACL-R performed (orthopaedic surgeons), or ACLdeficient patients treated (physical therapists) during the last 6 months

${ }^{c}$ The response options of whether the respondent had knowledge of guidelines guidelines/health care programmes outlining which patients should undergo an ACL-R was; "no", "yes international guidelines" "yes national guidelines" and "yes local guidelines". Multiple answers were allowed for the question

stated that they sometimes or often have contact with the treating physical therapist.

Regarding rehabilitation outcome, most of the orthopaedic surgeons ( 87 of $91,96 \%$ ) sometimes or often seek information about the outcome by asking the patient. Sixty-nine surgeons (78\% of 89 ) sometimes or often obtain the information by reading the patient's medical record, 74 surgeons ( $81 \%$ of 91 ) sometimes or often contact the treating physical therapist.

Eighty per cent of the physical therapists (296 of 368) stated that when they recommend ACL-R, they often communicate their recommendation to the patient, and $67 \%$
(234 of 348) sometimes or often communicate their recommendation to the orthopaedic surgeon.

\section{Discussion}

The most important finding of this study was that Swedish orthopaedic surgeons and physical therapists show agreement that young age, frequent physical activity participation (in work or spare time), and significant knee instability after a period of rehabilitation ( $>3$ months) are key ACL-R decision-making factors. The results from orthopaedic surgeons are similar to previous studies and existing guidelines $[19,25]$, although the findings of the present study provide previously unknown information about physical therapists opinions, showing that both professions share a common ground in the values of factors that are important for recommending ACL-R. The factors-open physes, recurrent swelling and instability in sports and ADL when rehabilitation attempts are unclear-received ratings that were the most diverse within professions. This might suggest that these factors in isolation are not considered important in the choice to recommend ACL-R. The factor sex was rated as equally important for both male and female patients, indicating that it does not affect the choice to recommend ACL-R.

The three factors that orthopaedic surgeons and physical therapists agreed were most important to the recommendation for ACL-R were: desire to return to contact or pivoting sports at high/elite level, instability in sports, or instability in ADL despite $>3$ months of rehab. This supports previous studies that have identified activity demands and instability as important factors [18-20]. Orthopaedic surgeons considered that a physically demanding occupation was a very important factor for recommending surgery (grading "3" twice as many times compared to "2"). Physical therapists also considered physically demanding occupation important, but not to the same extent (equal amount of " 2 " and "3" grades) which could be due to the fact that physical therapists in Sweden do not handle sick leave certificates and questions about return to work to the same extent as orthopaedic surgeons do (in Sweden, physical therapists do not write sick leave certificates).

Physical therapists rated patient suffers from significant knee joint instability in sports participation, despite rehabilitation (> 3 months) as very important (grading " 3 " twice as many times compared to "2"), but among orthopaedic surgeons that factor was less important (equal amount of " 2 " and "3" grades). That might reflect that physical therapy is often focused on rehabilitation training aimed at return to physical activity and sports participation [30].

Orthopaedic surgeons and physical therapists did not always reach clinical agreement about the importance of factors. Orthopaedic surgeons agreed that associated meniscus 
Table 2 Factors rated for their importance to recommend ACL-R

\begin{tabular}{|c|c|c|c|c|c|c|c|c|}
\hline \multirow[t]{2}{*}{ Factors } & \multirow[t]{2}{*}{$N^{\mathrm{a}}$} & \multicolumn{3}{|c|}{$\begin{array}{l}\text { Orthopaedic surgeons } \\
\text { Total }(n=98)\end{array}$} & \multirow[t]{2}{*}{$N^{\mathrm{a}}$} & \multicolumn{3}{|c|}{$\begin{array}{l}\text { Physical therapists } \\
\text { Total }(n=391)\end{array}$} \\
\hline & & $\begin{array}{l}\text { Rate } 2 \text { or } 3 \\
n(\%)\end{array}$ & $\begin{array}{l}\text { Rate } 2 \\
n\end{array}$ & $\begin{array}{l}\text { Rate } 3 \\
n\end{array}$ & & $\begin{array}{l}\text { Rate } 2 \text { or } 3 \\
n(\%)\end{array}$ & $\begin{array}{l}\text { Rate } 2 \\
n\end{array}$ & $\begin{array}{l}\text { Rate } 3 \\
n\end{array}$ \\
\hline \multicolumn{9}{|l|}{ Patient age } \\
\hline$<25$ & 91 & $81(89)$ & 36 & 45 & 370 & $298(80)$ & 144 & 154 \\
\hline $25-40$ & 90 & $68(76)$ & 50 & 18 & 356 & $234(66)$ & 175 & 59 \\
\hline$>40$ & 90 & $24(27)$ & 19 & 5 & 354 & $79(22)$ & 59 & 20 \\
\hline Open physes & 91 & $39(43)$ & 27 & 12 & 368 & $70(19)$ & 57 & 13 \\
\hline \multicolumn{9}{|l|}{ Sex } \\
\hline Male & 90 & $69(77)$ & 31 & 38 & 360 & $246(68)$ & 148 & 98 \\
\hline Female & 90 & $70(78)$ & 30 & 40 & 360 & $245(68)$ & 144 & 101 \\
\hline \multicolumn{9}{|l|}{ Wish to return to sport } \\
\hline \multicolumn{9}{|l|}{ Contact/pivoting } \\
\hline Elite level & 91 & $90(99)$ & 10 & 80 & 377 & $366(97)$ & 40 & 326 \\
\hline Recreational & 91 & $87(96)$ & 33 & 54 & 375 & $321(86)$ & 150 & 171 \\
\hline \multicolumn{9}{|c|}{ Non-contact/non-pivoting } \\
\hline Elite level & 91 & $64(70)$ & 37 & 27 & 374 & $250(67)$ & 163 & 87 \\
\hline Recreational & 91 & $39(43)$ & 25 & 14 & 371 & $75(20)$ & 59 & 16 \\
\hline Occupation & 92 & $88(96)$ & 18 & 70 & 373 & $324(87)$ & 150 & 174 \\
\hline Recurrent swelling 91 & & $42(46)$ & 26 & 16 & 371 & $218(59)$ & 155 & 63 \\
\hline \multicolumn{9}{|c|}{ Instability despite $>3$ months rehab, in } \\
\hline Sports & 93 & $91(98)$ & 27 & 64 & 376 & $366(97)$ & 107 & 259 \\
\hline ADL & 92 & $91(99)$ & 6 & 85 & 374 & $366(98)$ & 43 & 323 \\
\hline \multicolumn{9}{|c|}{ Instability (unclear if rehab) in } \\
\hline Sports & 92 & $40(43)$ & 22 & 18 & 376 & $165(44)$ & 118 & 47 \\
\hline ADL & 93 & $55(59)$ & 35 & 20 & 370 & $171(46)$ & 112 & 59 \\
\hline Patient insists & 90 & $30(33)$ & 24 & 6 & 368 & $90(24)$ & 75 & 15 \\
\hline OS/PT recommends $s_{b}$ & 91 & $70(77)$ & 48 & 22 & 371 & $295(80)$ & 194 & 101 \\
\hline \multicolumn{9}{|l|}{ Associated injuries } \\
\hline Meniscus & 90 & $74(82)$ & 31 & 43 & 368 & $267(73)$ & 160 & 107 \\
\hline Articular Cartilage & 90 & $52(58)$ & 33 & 19 & 367 & $221(60)$ & 137 & 84 \\
\hline Ligament & 90 & $74(82)$ & 35 & 39 & 363 & $267(74)$ & 159 & 108 \\
\hline
\end{tabular}

Answer options $0=$ "no surgery" to $3=$ "surgery" for orthopaedic surgeons, and $0=$ "low probability" to $3=$ "high probability" (to recommend surgery) for physical therapists. Bold-marked factors are considered important with clinical agreement (> $80 \%$ of raters answered " 2 " or " 3 "). Number of ratings for "2" or "3" are presented. Percentage is calculated for the total amount of respondents for each factor

$A C L-R$ anterior cruciate ligament reconstruction, $A D L$ activities of daily living, $O S$ orthopaedic surgeon, $P T$ physical therapist

${ }^{a}$ The total number of respondents for each factor

${ }^{b}$ Orthopaedic surgeons were asked about the factor "responsible physical therapist recommends reconstruction" and vice versa or ligament injuries were important factors to recommend ACL-R, while physical therapists did not agree regarding these factors. Physical therapists agreed that orthopaedic surgeon recommended ACL-R is an important factor, while orthopaedic surgeons rated physical therapist recommends ACL-R, slightly lower, (77\% agreement).

There was some "clinical disagreement" between orthopaedic surgeons and physical therapists, where about half of the respondents considered the factor as important for recommending ACL-R, while the other half rated it as not important (grades 1 or 2). There was clinical disagreement among orthopaedic surgeons more often than among physical therapists. Open physes (previously rated as a factor that was not important for recommendation of ACL-R according to American orthopaedic surgeons [19]) was in the present study rated as important by $43 \%$ of orthopaedic surgeons, and by $20 \%$ of physical therapists. The potential for growth abnormality or growth arrest following ACL-R 
Table 3 Factors revealed from the open-ended question

\begin{tabular}{|c|c|c|c|c|}
\hline \multirow[t]{2}{*}{$\begin{array}{l}\text { Categories } \\
\text { Subcategories }\end{array}$} & \multicolumn{2}{|c|}{$\begin{array}{l}\text { Orthopaedic surgeons, total amount } \\
\text { of times: } 89\end{array}$} & \multicolumn{2}{|c|}{$\begin{array}{l}\text { Physical therapists, total amount of } \\
\text { times: } 583\end{array}$} \\
\hline & Single: $n(\%)$ & $\begin{array}{l}\text { Combination: } \\
n^{\mathrm{a}}(\%)\end{array}$ & Single: $n(\%)$ & Combination: $n^{\mathrm{b}}(\%)$ \\
\hline \multicolumn{5}{|l|}{ Instability } \\
\hline Subjective $^{c}$ & $11(12)$ & $8(8)$ & $47(8)$ & $55(9)$ \\
\hline Rehab $^{\mathrm{d}}$ & $12(13)$ & $9(10)$ & $73(12)$ & $47(8)$ \\
\hline Working ${ }^{\mathrm{e}}$ & $2(2)$ & $5(6)$ & $9(1)$ & $35(6)$ \\
\hline $\mathrm{ADL}^{\mathrm{f}}$ & $3(3)$ & $5(6)$ & $19(3)$ & $46(8)$ \\
\hline \multicolumn{5}{|l|}{ Patient focus } \\
\hline Wishes $^{\mathrm{g}}$ & 0 & $4(4)$ & $4(<1)$ & $20(3)$ \\
\hline $\mathrm{QOL}^{\mathrm{h}}$ & 0 & 0 & $5(1)$ & $11(2)$ \\
\hline Symptoms ${ }^{\mathrm{i}}$ & 0 & $1(1)$ & $2(<1)$ & $20(3)$ \\
\hline Activity demands $\mathrm{s}^{\mathrm{j}}$ & $6(7)$ & $12(13)$ & $55(9)$ & $114(22)$ \\
\hline \multicolumn{5}{|l|}{ Other injuries } \\
\hline New injuries ${ }^{\mathrm{k}}$ & 0 & $1(1)$ & $2(<1)$ & $2(<1)$ \\
\hline Associated injuries ${ }^{1}$ & $1(1)$ & $2(2)$ & $1(<1)$ & $2(<1)$ \\
\hline \multicolumn{5}{|c|}{ Sociodemographic factors } \\
\hline $\mathrm{Age}^{\mathrm{m}}$ & 0 & $1(1)$ & $1(<1)$ & 15 \\
\hline Gender $^{\mathrm{n}}$ & 0 & 0 & 0 & $1(<1)$ \\
\hline Objective instability $^{\mathrm{o}}$ & $1(1)$ & $5(6)$ & $1(<1)$ & $3(<1)$ \\
\hline
\end{tabular}

Categorization of open-ended question of which factor, or combination of factors that are the most important to recommend ACL-R, including frequency of statements for each category. Each category is divided into "stated as a single factor" and "stated as combination of factors"

$A C L-R$ anterior cruciate ligament reconstruction, $A D L$ activities of daily living, $Q O L$ quality of life

${ }^{\mathrm{a}} n=89$. The total amount of times that orthopaedic surgeons mention factors. Percentage is calculated as percentage of the total amount of times as factors was mentioned

${ }^{\mathrm{b}} N=583$. The total amount of times that physical therapists mention factors. Percentage is calculated as percentage of the total amount of times as factors were mentioned

${ }^{c}$ Patient reports instability

${ }^{\mathrm{d}}$ Instability despite an adequate rehabilitation period

${ }^{\mathrm{e}}$ Instability in working situation

${ }^{\mathrm{f}}$ Instability in ADL

${ }^{g}$ Patient's wishes and/or motivation for ACL-R

${ }^{\mathrm{h}}$ Patients experience affected/lowered quality of life

iSymptoms as pain and/or swelling

${ }^{j}$ Wishes to return to high knee impact activity/high activity level or risk of involuntarily lowered activity

${ }^{\mathrm{j}}$ Risk of new injuries/symptoms (e.g., meniscal tear, developing early osteoarthritis)

${ }^{1}$ Associated injuries on meniscus or ligaments

${ }^{\mathrm{m}}$ Young age as a factor for ACL-R

${ }^{\mathrm{n}}$ Female sex as a factor for ACL-R

${ }^{\mathrm{o}} \mathrm{Knee}$ laxity tests measured in clinical setting in children with open physes is debated, and consequently, there is strong debate about whether ACL-R is indicated or not $[3,5]$. Open physes was among the factors with the highest disagreement among orthopaedic surgeons, which could reflect this uncertainty. It could also reflect that the factor might not be important alone, but could affect the decision if an ACL-R should be recommended due to other factors. Another factor that had high clinical disagreement among orthopaedic surgeons was associated injuries to articular cartilage. Physical therapists disagreed on the same factors as orthopaedic surgeons, except for open physes, where $81 \%$ of the physical therapists rated it as not important.

Instability/giving way was consistently reported as the most important factor for recommending ACL-R, which is consistent with previous research [2, 19, 20, 25]. Orthopaedic surgeons and physical therapists often reported instability despite adequate rehabilitation as a single factor influencing their treatment decision-making, which is in line with 


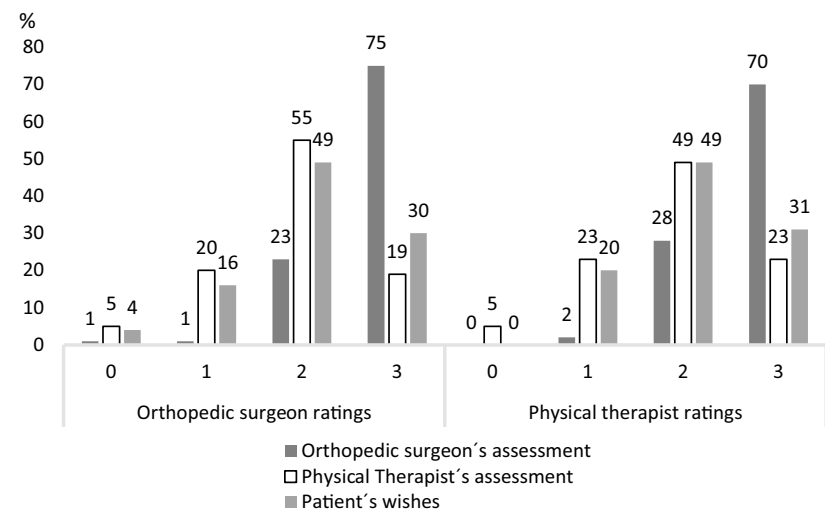

Fig. 1 Orthopaedic surgeons and physical therapists ratings of; "To which degree do you believe the decision to treat a patient by ACL-R is based upon the orthopaedic surgeons/physical therapists' assessments, and the patient's wishes". Rating scale $0-3$, anchored "to a very low extent" and "to a very high extent". Figures are expressed as percentage of the total amount of responses

Swedish recommendations [1]. Orthopaedic surgeons and physical therapists placed slightly different emphasis on the importance of activity demands. Physical therapists rated activity demands as the single most important factor (e.g., patients returning to high knee impact activity) and considered it important as part of a combination of important factors (generally in combination with instability) to a greater extent than orthopaedic surgeons. There is argument that ACL-R increases the chance of patients returning to previous sports activity and level, and lowers the risk of instability and giving way, compared to nonsurgical treatment [5]. However, the literature is not definitive, and other studies have shown that ACL-R might not be necessary to return to previous sports activity and level $[10,11]$.

It is common for orthopaedic surgeons and physical therapists to collaborate in the treatment of musculoskeletal conditions and for orthopaedic surgeons to refer patients to physical therapists [8]. Orthopaedic surgeons and physical therapists highly rated the impact of the other profession's assessment in the decision-making. This is important in the light of previous studies that show that collaborative practice have a positive effect on inter-professional communication, and can enhance the quality of care [17].

Orthopaedic surgeons and physical therapists also valued the patient's wishes in the treatment decision-making process. Shared decision-making in health care is important $[6,12,24,28]$, and a shared decision leads to better treatment results [15]. But even with the patient being involved in the decision process, there is no guarantee that he/she is informed of the options in a satisfying way $[29,30]$. Therefore, an evaluation of how patients with ACL injury consider their role in the treatment decision-making process would complete the present study.
Since this study is conducted in Sweden, the generalizability to other contexts might be questionable. In Sweden, it is common for collaboration between orthopaedic surgeons and physical therapists, which improves communication [17], but might not be as common in other countries.

Despite thorough reviewing by an expert panel and pilot testing, the construction of the survey may not have been optimal for the rating of factors influencing the treatment decision. Answer options for the factors in the survey were anchored "no surgery" and "surgery" for orthopaedic surgeons and "little probability that I would recommend ACL reconstruction" and "great probability that I would recommend ACL reconstruction" for physical therapists. The "surgery"/"great probability that I would recommend ACL reconstruction" option was intended to indicate that the factor was important for recommending surgery as treatment, but it might have been possible that the "no surgery" option for orthopaedic surgeons was either interpreted as a factor important to not choose surgery, or that the factor was not important in the recommendation of ACL-R. Because of this, we excluded the "no surgery" data from our analysis to avoid misinterpreted data and improve the reliability of the analyzed data.

Providing predetermined factors may have directed respondents to certain answers. The complexity of a clinical decision is not easily summed up in a survey, and consequently, the result might be a simplified reflection of how the real life decision to recommend ACL-R is taken [19]. To account for this, explore some of the complexity of the decision-making process, we included the open-ended question, which gave a slightly different picture of the level of importance put on different factors.

The intention was to reach as many Swedish orthopaedic surgeons and physical therapists who treated patients with ACL injury as possible. Since almost all orthopaedic surgeons who perform ACL-R in Sweden, are registered in the Swedish National Knee Ligament Register, we believe we have reached the majority of the orthopaedic surgeons that perform ACL-R in Sweden. There are approximately 21,000 licenced physical therapists in Sweden working across different settings [26]. There is no way of knowing to what extent we succeeded in reaching physical therapists treating patients with ACL injury, since there is no specific registration of these physical therapists. Because of that, an accurate response rate is uncertain.

This study shows that orthopaedic surgeons and physical therapist mainly agree on factors that are important to recommend ACL reconstruction, with some slight differences which might be due to different point of views. Physical therapists often meet each patient more frequently, and might, therefore, emphasise other aspects than the orthopaedic surgeons, in the treatment choice. Collaboration between the two groups could be valuable in the choice of which 
treatment to recommend, to enlighten different aspects and thus provide the best recommendations for the patients.

\section{Conclusion}

Orthopaedic surgeons and physical therapists rated patients' wishes to return to contact/pivoting sports, knee joint instability in physical activity or activities of daily living despite adequate rehabilitation, physically demanding occupation, and young age as important factors for their decision to recommend ACL-R. The most prominent single factor influencing the decision was "knee instability". Both professions consider their own and each other's assessment as important for the decision to recommend ACL-R.

Acknowledgements The authors wish to acknowledge and thank Gunilla Leidelöf, for assistance in sending out invitations to participant. We also wish to thank the Swedish National ACL register, the Society for Physical Activity and Sports Medicine and the Football Physiotherapists Association for assistance with contact information to respondents in the study.

Author contributions All authors were involved in the development of the study design and development of the questionnaire. AF and JK were involved in the data collection. HTG did the statistical analysis. HTG has been mainly responsible for the manuscript drafts, and all authors have revised the manuscript critically, for important intellectual content.

Funding No funding.

\section{Compliance with ethical standards}

Conflict of interest The authors declare that they have no conflict of interest.

Ethical approval This study had ethical approval from the Regional Ethical Review Board Dnr 2014 (71/31).

Informed consent Informed consent was obtained from all individual participants included in the study.

Open Access This article is distributed under the terms of the Creative Commons Attribution 4.0 International License (http://creativeco mmons.org/licenses/by/4.0/), which permits unrestricted use, distribution, and reproduction in any medium, provided you give appropriate credit to the original author(s) and the source, provide a link to the Creative Commons license, and indicate if changes were made.

\section{References}

1. Ahldén M, Kvist J, Samuelsson K, Eriksson KO, Karlsson J (2014) Individualiserad terapi viktigt vid främre korsbandsskada. Läkartidningen 111:1440

2. Beaufils P, Hulet C, Dhenain M, Nizard R, Nourissat G, Pujol N (2009) Clinical practice guidelines for the management of meniscal lesions and isolated lesions of the anterior cruciate ligament of the knee in adults. Orthop Traumatol Surg Res 95:437-442

3. Collins MJ, Arns TA, Leroux T, Black A, Mascarenhas R, Bach BR Jr et al (2016) Growth abnormalities following anterior cruciate ligament reconstruction in the skeletally immature patient: a systematic review. Arthroscopy 8:1714-1723

4. Domes CM, Kruger CL (2015) Therapists, trainers, and acupuncturists: focused review for the orthopedic surgeon. Orthopedics 38:e1121-e1126

5. Dunn KL, Lam KC, Valovich McLeod TC (2016) Early operative versus delayed or nonoperative treatment of anterior cruciate ligament injuries in pediatric patients. J Athl Train 51:425-427

6. Elwyn G, Barr PJ, Grande SW, Thompson R, Walsh T, Ozanne EM (2013) Developing CollaboRATE: a fast and frugal patientreported measure of shared decision making in clinical encounters. Patient Educ Couns 93:102-107

7. Fitzgerald GK, Axe MJ, Snyder-Mackler L (2000) A decisionmaking scheme for returning patients to high-level activity with nonoperative treatment after anterior cruciate ligament rupture. Knee Surg Sports Traumatol Arthrosc 8:76-82

8. Freburger JK, Holmes GM, Carey TS (2003) Physician referrals to physical therapy for the treatment of musculoskeletal conditions. Arch Phys Med Rehabil 84:1839-1849

9. Frobell RB, Roos EM, Roos HP, Ranstam J, Lohmander LS (2010) A randomized trial of treatment for acute anterior cruciate ligament tears. N Engl J Med 363:331-342

10. Frobell RB, Roos HP, Roos EM, Roemer FW, Ranstam J, Lohmander LS (2015) Treatment for acute anterior cruciate ligament tear: five year outcome of randomised trial. Br J Sports Med 49:700

11. Grindem H, Eitzen I, Engebretsen L, Snyder-Mackler L, Risberg MA (2014) Nonsurgical or surgical treatment of ACL injuries: knee function, sports participation, and knee reinjury: the Delaware-Oslo ACL cohort study. J Bone Jt Surg Am 96:1233-1241

12. Holland WC, Hunold KM, Mangipudi SA, Rittenberg AM, Yosipovitch N, Platts-Mills TF (2016) A prospective evaluation of shared decision-making regarding analgesics selection for older emergency department patients with acute musculoskeletal pain. Acad Emerg Med 23:306-314

13. Hurd WJ, Axe MJ, Snyder-Mackler L (2008) A 10-year prospective trial of a patient management algorithm and screening examination for highly active individuals with anterior cruciate ligament injury: part 1, outcomes. Am J Sports Med 36:40-47

14. Hurd WJ, Axe MJ, Snyder-Mackler L (2008) A 10-year prospective trial of a patient management algorithm and screening examination for highly active individuals with anterior cruciate ligament injury: part 2, determinants of dynamic knee stability. Am J Sports Med 36:48-56

15. Hutchinson RH, Barrie JL (2015) The effects of shared decision making in the conservative management of stable ankle fractures. Injury 46:1116-1118

16. Klinge SA, Sawyer GA, Hulstyn MJ (2013) Essentials of anterior cruciate ligament rupture management. R I Med J (2013) 96:28-32

17. Longstaffe R, Slade Shantz J, Leiter J, Peeler J (2015) Surgeontherapist communication: do all members see eye-to-eye? Phys Sportsmed 43:381-387

18. Mahnik A, Mahnik S, Dimnjakovic D, Curic S, Smoljanovic T, Bojanic I (2013) Current practice variations in the management of anterior cruciate ligament injuries in Croatia. World J Orthop 4:309-315

19. Marx RG, Jones EC, Angel M, Wickiewicz TL, Warren RF (2003) Beliefs and attitudes of members of the American Academy of Orthopaedic Surgeons regarding the treatment of anterior cruciate ligament injury. Arthroscopy 19:762-770 
20. Meuffels DE, Poldervaart MT, Diercks RL, Fievez AW, Patt TW, Hart CP et al (2012) Guideline on anterior cruciate ligament injury. Acta Orthop 83:379-386

21. Moksnes H, Snyder-Mackler L, Risberg MA (2008) Individuals with an anterior cruciate ligament-deficient knee classified as noncopers may be candidates for nonsurgical rehabilitation. $\mathrm{J}$ Orthop Sports Phys Ther 38:586-595

22. Noyes FR, Matthews DS, Mooar PA, Grood ES (1983) The symptomatic anterior cruciate-deficient knee. Part II: the results of rehabilitation, activity modification, and counseling on functional disability. J Bone Jt Surg Am 65:163-174

23. Noyes FR, Mooar PA, Matthews DS, Butler DL (1983) The symptomatic anterior cruciate-deficient knee. Part I: the longterm functional disability in athletically active individuals. J Bone Jt Surg Am 65:154-162

24. Sandman L, Munthe C (2009) Shared decision-making and patient autonomy. Theor Med Bioeth 30:289-310

25. Shea KG, Carey JL, Richmond J, Sandmeier R, Pitts RT, Polousky JD et al (2015) The American Academy of Orthopaedic Surgeons evidence-based guideline on management of anterior cruciate ligament injuries. J Bone Jt Surg Am 97:672-674
26. Socialstyrelsen (2016) Tillgång på fysioterapeuter 2013. Tillgång på fysioterapeuter 2013. Accessed $29 \mathrm{Jul} 2016$

27. Swirtun LR, Eriksson K, Renstrom P (2006) Who chooses anterior cruciate ligament reconstruction and why? A 2-year prospective study. Scand J Med Sci Sports 16:441-446

28. The Swedish ACL register (2016) Annual report 2015. Svenska korsbandsregistret. https://www.artroclinic.se/info/rapport201 5.pdf. Accessed 12 Sept 2016

29. Washington K, Shacklady C (2015) Patients' experience of shared decision making using an online patient decision aid for osteoarthritis of the knee-a service evaluation. Musculoskelet Care 13:116-126

30. Weckbach S, Kocak T, Reichel H, Lattig F (2016) A survey on patients' knowledge and expectations during informed consent for spinal surgery: can we improve the shared decision-making process? Patient Saf Surg 10:15

31. Yabroudi MA, Irrgang JJ (2013) Rehabilitation and return to play after anatomic anterior cruciate ligament reconstruction. Clin Sports Med 32(1):165-175 